\title{
Rationale and Implications of Psychoactive Substances Use Among Commercial Road Transport Workers in Lokoja, Nigeria
}

\author{
Ajibade David \\ Department of Sociology, \\ Kogi State University, \\ Anyigba, Nigeria \\ Adefolaju Toyin \\ Department of Sociology, \\ Ekiti State University, \\ Ado-Ekiti, Nigeria
}

Doi: 10.2478/mjss-2018-0107

\begin{abstract}
This study investigates the rationale and implications of psychoactive substances use among commercial road transport workers in Lokoja, Nigeria, using cross-sectional survey research design. The study population comprises of trailer drivers, taxi drivers, tipper drivers and long distance bus drivers registered in Lokoja. However, due to variation in the population of each of the study groups, a quota of forty five (45) participants were allotted to each of the groups (totalling one hundred and eighty, 180) in order to prevent over-representation of one group over the other. Selection of respondents at garage/park level was however done using purposive sampling technique. Data were collected using semi-structured questionnaire and statistically analysed using frequencies, percentage, and weighted means. Results of the study show that majority of the respondents used psychoactive substances to overcome depression, stay awake while driving, overcome daily problems and for pleasure. These were however found to sometimes result to alteration in the moods and emotional state of the respondents, road traffic accidents, hangover and further involvement in substances usage. In view of these findings, it is recommended that Government should intensify campaign through print and electronic media as well as by organising seminar and workshop for members of commercial road transport workers not only in the study area but also in Nigeria generally, on the risks (social, psychological and health) of psychoactive substance usage.
\end{abstract}

Keywords: Psychoactive substances, Road transport workers, Road traffic accident, Lokoja, Nigeria

\section{Introduction}

Transport services sector in Nigeria comprising four sub sectors- road, rail, sea and air transportcontributes 1.58 percent of the Gross Domestic Products (GDP) and employs 5.99 percent of total labour force (National Bureau of Statistics, NBS, 2016). This study focuses on road transport, a sub sector, almost wholly under private ownership and predominantly in the informal economy both as regards finance and labour. Road transport accounts for 91 percent of passenger traffic and 96 percent of freight traffic (Hisam, 2006). The sector also contributes to the government revenues through taxes and duties on import of vehicles and parts, petroleum products and fees on ownership and operation of vehicles. According to the NBS (2016), only road related revenue collection amount to 21.89 percent of the transport sector contribution to the GDP.

Road transport labour force comprises of male (and female in rare case) wage workers, selfemployed operators owning vehicle purchased on loans either from money lenders or from small 
entrepreneur on exploitation terms (Hisam, 2006). The transport sector is marred with damaging working condition-long and irregular working hours (Girotto, Mesas, deAndrade \& Birolim., 2014; and Girotto, deAndrade, Mesas, Gonzalez \& Guidoni, 2015). Often the workers (on the inter-city route) are on the vehicle for as long as 26 hours at a stretch. Their work include not just driving or assisting passengers but loading/unloading, cleaning, maintenance, and any other work related to ensuring safety of vehicle and its cargo and passengers. On intra-city routes, taxi drivers, for instance, work an average of 12 hours a day with little or no time to rest (Hisam, 2006).

Due to the nature of their job, it is observable that many of the commercial road transport workers often augment their strength with psychoactive substances such as distilled spirits and local alcoholic beverage and concoctions like ogogoro, burukutu, palmwine; beer, marijuana, cocaine, heroin, etc. This observation is further reinforced with the visual evidence of availability and sale of the substances in parks/garages in most urban centres despite its prohibition by government (Rasheed \& Ismaila, 2012).

Conceptually, psychoactive substance is any substance/drug that modifies or effect change in mood or behaviour (Witters, Venturelli \& Hanson, 2006; Ebie, 2008). Generally, People uses psychoactive substances for many reasons including for pleasure, to keep awake while driving, to reduce stress, to feel grown up or fit in into peer group culture, etc (Adadu, Akpama \& Ekanem, 2012; Okpataku, 2016). In spite of these, psychoactive substance usage has been found to be a leading source of preventable morbidity and untimely mortality globally (Centre for Disease Control and Prevention, 2012), as its usage has been associated with cancer of the lungs, respiratory and other cardiac problems (Unackwukwu \& Nwankwo, 2003). In addition, people using psychoactive substances are also more likely to engage in risky behaviour such as unprotective sexual activity, driving under the influence of drugs which sometimes resulted to road traffic accident, criminal activities, engaging in violent behaviours, etc (Ihezue, 1988; Hanson \& Engs, 1992; Presley, Meilman \& Lyeria, 1993; Fawibe \& Shittu, 2011; Usman \& Ipinmoye, 2015). Globally, it has become a major public health concern as it has been estimated that nearly a third of the world's population aged 15 years and above uses psychoactive substance (United Nations Office on Drugs and Crime, 2016).

The prevalence of psychoactive substances usage has however been hung on sociodemographics, psychological, environmental and socio-cultural factors such as low socio-economic status (Rozi, Butt, \& Akhtar, 2007; Mergen, Mergen, Tavil, Ongel \& Tan, 2011; Thakur, Prinja, Bhatnagar \& Sinha, 2013); being a male (Sen \& Basu, 2000; Peltzer, 2001; Sinha \& Gupta, 2007); older age (Peltzer, 2001); depression and anxiety (Halperin, Smith, Heiligenstein, Brown \& Fleming, 2010; Saravana \& Heldhy, 2014; and Breslau, Kilbey \& Andreski, 1991); violence experience including intimate partner violence (Caleyachetty, Echouffo-Tcheugui, Stephenson \& Muennig, 2014); obesity (Ansari, Labeeb \& Kotb, 2012); peer pressure and polygamous family background (Aina \& Olorunshola, 2008); desire to remain awake at night (Rasheed, 2010) and broken homes (Haukkala, Utela, Vartiainen, Mcalister \& Knekt, 2000; Mee, 2014; and Didilescu, Inagaki, Sfeateu, Hanganu \& Virtanen, 2014). Apart from these, industrialisation, urbanisation and increased exposure to western life style have also been found to contribute to the increasing trend of psychoactive substances usage with alcohol and cigarette acting as gateway drugs to the use of other substances such as cocaine, heroin, amphetamine, inhalants and hallucinogens (Abiodun, Adelekan, Ogunremi, Oni \& Obayan, 1994).

In view of the foregoing, an understanding of the types of psychoactive substances ever/never used, reasons for the use of psychoactive substances, frequency of usage and its effects most especially among commercial road transport workers is therefore necessary in order to recommend appropriate control measures that will help to discourage future use and thus improve safety in transport industry generally. Based on this and since such study has not been empirically performed in Lokoja before, the present study therefore strive to investigate into this phenomenon.

\section{Research Questions}

The following questions guide this study:

(i) What are the types of psychoactive substances ever/never used by commercial road transport workers in Lokoja? 
(ii) What are the reasons for the use of such psychoactive substances?

(iii) How frequent do they use such psychoactive substances?

(iv) What are the effects of psychoactive substance usage on commercial road transport workers?

\section{Objectives of the Study}

The general objective of this study is to examine the rationale and implications of psychoactive substances use among commercial road transport workers in Lokoja, Nigeria. The specific objectives are to:

(i) identify the types of psychoactive substances ever/never used by commercial road transport workers in Lokoja

(ii) find out the reasons for the use of such psychoactive substances

(iii) investigate the frequency of using such psychoactive substances, and

(iv) examine the effects of psychoactive substances usage on commercial road transport workers.

\section{Theoretical Framework}

\subsection{Sub cultural theory}

This work is anchored on the sub cultural theory. Sub cultural theory is associated with the work of Becker (1953). The main argument of the theory is that involvement in a particular social group whose members have attitudes favourable to psychoactive substances use is the key factor in fostering one's own psychoactive substances use and that involvement in a group whose members have negative attitudes toward psychoactive substances use tends to discourage such use. Psychoactive substances use is thus encouraged in certain social circle and actively discouraged in others. In relating the theory to the current study, commercial road transport workers are group of professional drivers. However, due to the nature of their job (fatigue prone) they often augment their strength with psychoactive substances as an adjustment strategy to stressful job. Commercial road transport workers thus have positive attitude towards psychoactive substance use.

\section{Research Methods}

\subsection{Brief description of the study area}

This study was carried out in Lokoja, Nigeria between February and March, 2017. Lokoja is the capital of Kogi State in North Central Nigeria and it lies between $7.8023^{\circ} \mathrm{N}$ of the equator and $6.7333^{\circ} \mathrm{E}$ of the Meridian. Lokoja is selected for the study because it connects the Nigeria Federal Capital Territory with twenty two (22) southern states and therefore has a high proportion of articulated vehicles and buses coming in and out of the town from and to other parts of the country.

\subsection{Research design, study population, sample size and sampling technique}

This study used cross sectional survey design. The design is considered apt since the study cut across different categories of road transport workers in the study area. The study population comprises of trailer drivers, taxi drivers, tipper drivers and long distance bus drivers registered in Lokoja, Nigeria. However, due to variation in the population of each of the study groups, a quota of forty five (45) participants were allotted to each of the groups (totalling one hundred and eighty, 180 ) in order to prevent over-representation of one group over the other. Selection of respondents at garage/park level was done using purposive sampling technique. The choice to use purposive sampling technique is hinged on the fact that it allows the researchers to choose any members of the study group at will. Therefore in this study only members of the study group met at the garage/park during the period of the study were used as respondents. 


\subsection{Research instrument}

Semi-structured questionnaire was used to obtain data. The questionnaire was divided into five sections. Section A consists of questions on socio-demographic characteristics of the respondents. It aims to get information from the respondents regarding their gender, age, marital status, educational level, religious affiliation, years of driving experience, ethnic group, driving hours and income. Section B elicits information on types of psychoactive substances ever/never used by the respondents. There are eight items in this section and respondents were asked to rate the items using two point rating scale (where 1 means 'never used', and 2 means 'ever used'. Section C focuses on the frequency of using psychoactive substances. There are four items in this section namely 'daily', 'weekly', 'monthly', and 'others'. Respondents were asked to choose one of the items. Section D concentrates on the reasons for the use of psychoactive substance. There are ten items in this section and respondents were asked to rate the items using four points rating scale (where 1 means 'strongly disagree', 2 means 'disagree', 3 means 'agree', and 4 means 'strongly agree'. Section $E$ focuses on the effects of psychoactive substance use on the respondents. There are eleven items in this section and respondents were asked to rate the item using three point rating scale (where 1 means 'never', 2 means 'sometimes' and 3 means 'always'.

However before using this instrument, it was subjected to pilot testing (to determine its level of reliability) where 20 copies of the questionnaire were administered on 20 respondents in park/garage different from the one sampled; and a cronbach alpha of 0.81 was obtained.

\subsection{Statistical analysis}

The data collected were process using Statistical Package for Social Sciences (SPSS) version 20, and statistically analysed using frequencies, percentages and weighted mean to describe respondents socio-demographic characteristics, psychoactive substance awareness distribution, respondents age and feeling at first usage of psychoactive substances, respondents access to psychoactive substances, respondents reasons for the use of psychoactive substances and effects of psychoactive substances use. The formulated hypotheses were tested using Spearman rank correlation and chi-square.

By and large, the study conformed to the guiding principles of social research ethics which include autonomy, justice and avoidance of malfeasance. Respondents were given latitude to decide whether to participate in the research.

\section{Results}

In this study, a total of one hundred and eighty (180) questionnaires were administered out of which one hundred and thirty (130) representing 72.2 percent were suitable for analysis and the remaining fifty (27.8 percent) were invalid and not used in the analysis. The analyses done in this study are in two parts. Part A focuses on the analysis of the respondent's socio-demographic data. Part B centres on the analysis of each of the specific objectives of the study.

\subsection{Part A: Socio-demographic profile of the respondents}

Table 1: Socio-Demographic Profile of the Respondents

\begin{tabular}{|l|l|c|c|}
\hline Variables & Characteristics & Frequency & Percent (\%) \\
\hline \multirow{3}{*}{ Gender } & Male & 130 & 100 \\
& Female & 00 & 00 \\
& Total & 130 & 100.0 \\
\hline \multirow{4}{*}{ Age (in year) } & Less than 20 years & 1 & 0.8 \\
& $20-29$ years & 20 & 15.4 \\
& $30-39$ years & 49 & 37.7 \\
& $40-49$ years & 40 & 30.8 \\
& 50 years and above & 20 & 15.4 \\
\hline
\end{tabular}




\begin{tabular}{|c|c|c|c|}
\hline Variables & Characteristics & Frequency & Percent (\%) \\
\hline & Total & 130 & 100.0 \\
\hline \multirow{6}{*}{ Marital status } & Married & 60 & 46.2 \\
\hline & Never married & 16 & 12.3 \\
\hline & Divorced & 21 & 16.2 \\
\hline & Separated & 20 & 15.4 \\
\hline & Widowed & 13 & 10.0 \\
\hline & Total & 130 & 100.0 \\
\hline \multirow{5}{*}{ Education Level } & No formal education & 22 & 16.9 \\
\hline & Primary school edu. & 58 & 44.6 \\
\hline & Secondary/Technical edu & 38 & 29.2 \\
\hline & Tertiary Education & 12 & 9.2 \\
\hline & Total & 130 & 100.0 \\
\hline \multirow{5}{*}{ Religious Affiliation } & Christianity & 47 & 36.2 \\
\hline & Islam & 58 & 44.6 \\
\hline & Traditional African Religion & 24 & 18.5 \\
\hline & Others & 1 & 0.8 \\
\hline & Total & 130 & 100.0 \\
\hline \multirow{5}{*}{ Driving Experience (in years) } & 2 - 4years & 27 & 20.8 \\
\hline & $5-7$ years & 59 & 45.4 \\
\hline & $8-10$ years & 31 & 23.8 \\
\hline & 11 years and above & 13 & 10 \\
\hline & Total & 130 & 100.0 \\
\hline \multirow{5}{*}{ Ethnic Group } & Yoruba & 41 & 31.5 \\
\hline & Hausa & 63 & 48.5 \\
\hline & & 16 & 12.3 \\
\hline & Others & 10 & 7.7 \\
\hline & Total & 130 & 100.0 \\
\hline \multirow{5}{*}{ Driving Hours } & Less than 4 hours & 13 & 10.0 \\
\hline & $4-6$ hours & 41 & 31.5 \\
\hline & $7-9$ hours & 61 & 46.9 \\
\hline & 10 hours and above & 15 & 11.5 \\
\hline & Total & 130 & 100.0 \\
\hline \multirow{8}{*}{ Monthly income (in naira) } & Below 10,000 & 2 & 1.54 \\
\hline & $10,001-15,000$ & 1 & 0.77 \\
\hline & $15,001-20,000$ & 9 & 6.92 \\
\hline & $20,001-25,000$ & 68 & 52.31 \\
\hline & $25,001-30,000$ & 38 & 29.23 \\
\hline & Above 30,000 & 5 & 3.85 \\
\hline & Undisclosed & 7 & 5.38 \\
\hline & Total & 130 & 100.0 \\
\hline
\end{tabular}

Source: Field Survey, 2017.

Table 1 show the socio-demographic profile of the respondents. The table reveals that all the respondents were male. This indicates that women have not been venturing into commercial driving career in the study area. Culturally, some jobs have been observed to be exclusively reserved for a particular gender. For example, tasks that are energetic are mostly assigned to the male gender, while those that require patience and less energy exertion are ethically meant for the female. The finding of this study indicates that commercial driving is a manly work in the study area. The current age of the respondents show that most (37.7 percent) of the respondents were within age 30-39 years, about 30.8 percent were within ages 40-49 years, 15.4 percent were age 20-29 years, and 50 years and above while the remaining 0.8 percent were of age less than 20 years. This result indicates that most of the respondents are young and they are in their productive age.

Respondents' marital status revealed that most (46.2 percent) of them are still married, about 16.2 percent were divorced, 15.4 percent were separated from their partners, 12.3 percent were never married while the remaining 10.0 percent have lost their partners due to death (widowed). A situation where majority of the respondents are married indicates that they are matured and 
responsible adults. On respondents' educational level, most (44.6 percent) of them have the primary school certificate, about 29.2 percent have secondary/technical school certificate, 16.9 percent never attended any school while the remaining 9.2 percent have tertiary education certificate such as National Diploma (ND) certificate, Nigeria Certificate in Education (NCE), and University degrees. This result indicates that majority of the respondents are fairly literate. Further enquiries were made from some of the respondents who didn't have any educational certificate on why they didn't attend any school, and from those that have primary/secondary certificates on why they didn't further their studies. Some of the reasons given by the respondents include financial difficulties, lack of interest in further studies, parental abandonment and untimely death of parents.

Respondents' religious affiliation shows that most (44.6 percent) of them were Muslim, about 36.2 percent were Christian, 18.5 percent belong to various traditional African religion, while the remaining 0.8 percent were atheist. The high proportion of the respondents who are Muslims over Christian, traditional African religion worshippers and atheist is an indication that there are more Muslims among the commercial road transport workers in the study area. As regards respondents year of driving experience, most (45.4 percent) of them have between 5-7 years of driving experience, about 23.8 percent have between 8-10 years of driving experience, 20.8 percent have between 2-4 years of driving experience while the remaining 10.0 percent have between 11 years and above driving experience. In sum, although those respondents who have driving experience of between 5-7 years are in the majority, however other respondents equally have different years of driving experiences. This indicates that commercial road drivers sampled in this study have different number of years of driving experience necessary to make their driving end in success.

Also from the table 1 above, the ethnic group of the respondents shows that almost half (48.5 percent) of them were Hausa, about 31.5 percent were Yoruba, 12.3 percent were Igbo while the remaining 7.7 percent were from other ethnic groups in Nigeria. The high proportion of the respondents of Hausa ethnic group is as a result of the fact that the study area fall within the Hausa region of the North Central Nigeria. With regards to the respondents' driving hours, most (46.9) of them drove between 7-9 hours, about 31.5 percent drove for 4- 6 hours, 11.5 percent drove for 10 hours and above while the remaining 10.0 percent drove for less than 4 hours. This result indicate that majority of the respondents sampled in this study drove between 4-6 hours non-stop. On respondents' monthly income, a little more than half (52.3 percent) earned between N20,001$\mathrm{N} 25,000$, about 29.23 percent earned between N25,001- N30,000; 6.9 percent earned between $\mathrm{N} 15,001$ - N20,000 while the remaining 5.38 percent of the respondents did not disclosed their income. This result indicates that those respondents who earned between N20, 001- N25, 000 are in majority. This however shows that commercial road transport workers have lower income compared to the income of civil and public sector workers in the country.

In sum, the socio-demographic profile of the respondents revealed that all of them are male, and majority are between age 30-39 years, married, have primary school certificate, muslim, have between 5-7 years of driving experience, were Hausa by ethnic group, drove for between 7-9 hours daily, and earn income of between 20,001-25,000 naira monthly.

Apart from the foregoing, each of the specific objectives of the study were also analysed in part B aspect of the paper below:

\subsection{Part B: Analysis of each of the specific objectives of the study.}

\subsubsection{Objective 1: Types of psychoactive substances ever/never used by the respondents}

Before examining the types of psychoactive substances ever/never used by the respondents, efforts were first of all made to know whether respondents have ever heard of any of the psychoactive substances such as cigarettes, beer, distilled spirits and local alcoholic beverage and concoctions such as Ogogoro, Burukutu, Jedi, Paraga, Opa eyin, cocaine, etc before and the sources of their information about the substances. The results of the enquiries shows that majority (93.1 percent) of the respondents responded in the affirmative while the remaining (6.9 percent) responded in the negative. This finding indicates that majority of the respondents had knowledge of psychoactive substances before been commercial road transport workers. This also means that 
psychoactive substances are not a strange thing to about 93.1 percent of the sampled population. As regards the sources of information about psychoactive substances, about 33.9 percent of the respondents heard about it through friends/relatives while 32.2 percent heard about psychoactive substances from radio programme. Other sources included health workers (15.7 percent) and television ( 9.9 percent) while 10 respondents (8.3 percent) read about psychoactive substances in newspapers. Enquiries were also made from the respondents on the extent of their access to psychoactive substances if needed; and the results of the enquiries revealed that majority of the respondents have very easy access to cigarette (with weighted mean of 4.56$)$, followed by beer ( $x=$ $4.44)$, and caffeine (kolanut) $(x=4.37)$ and least access to anabolic steroid $(x=1.85)$. Further enquiries were made from the respondents on whether they have ever used any of the psychoactive substances; and the results show that almost all the respondents (93.8 percent) answered in the affirmative while the remaining 6.2 percent responded in the negative. Efforts were also made to know the type of psychoactive substances ever/never used by the respondents who responded in the affirmative and the results is shown in table 2 below.

Table 2: Distribution of Respondents on Psychoactive Substance Ever/Never Used

\begin{tabular}{|c|c|c|c|c|c|c|c|}
\hline $\begin{array}{c}\text { No. in the } \\
\text { Questionnaire }\end{array}$ & Substances & $\begin{array}{c}\begin{array}{c}\text { Ever } \\
\text { used }\end{array} \\
2\end{array}$ & \begin{tabular}{|c|}
$\begin{array}{c}\text { Never } \\
\text { Used }\end{array}$ \\
1
\end{tabular} & Fx & N & $\bar{x}$ & Rank \\
\hline 1 & Cigarette & 99 & 23 & 221 & 122 & 1.81 & $1^{\mathrm{st}}$ \\
\hline 2 & Beer & 97 & 25 & 219 & 122 & 1.80 & $2^{\text {nd }}$ \\
\hline 3 & $\begin{array}{l}\text { Distilled spirits and local alcoholic beverage and } \\
\text { concoctions such as Ogogoro, Burukutu, Palmwine, } \\
\text { Jedi, Paraga, Agbo iba and Opa eyin }\end{array}$ & 94 & 28 & 216 & 122 & $\mid 1.77$ & $3^{\text {rd }}$ \\
\hline 8 & Caffeine (kolanut) & 84 & 38 & 206 & 122 & 1.69 & $4^{\text {th }}$ \\
\hline 4 & Marijuana (Indian hemp) & 44 & 78 & 166 & 122 & 1.36 & $5^{\text {th }}$ \\
\hline 7 & Anabolic steroid & 18 & 104 & 140 & 122 & 1.15 & $6^{\text {th }}$ \\
\hline 5 & Cocaine & 16 & 106 & 138 & 122 & 1.13 & $7^{\text {th }}$ \\
\hline 6 & Heroine & 6 & 116 & 128 & 122 & 1.05 & $8^{\text {th }}$ \\
\hline
\end{tabular}

Source: Field Survey, 2017

Table 2 show the distribution of respondents by the psychoactive substances ever/never used. The result from the table revealed that majority of the respondents had ever smoke cigarette (ranked first with weighted mean of 1.81), drank beer $(x=1.80)$, distilled spirits and local alcoholic beverage $(x=1.77)$, and ate kolanut $(x=1.69)$ while heroine is the least used psychoactive substances by the respondents with the weighted mean of 1.05 .

\subsubsection{Objective 2: Frequency of Using Psychoactive Substances by the Respondents}

Table 3: Respondents Age and Feeling at First Usage of Psychoactive Substances and Current Usage Pattern

\begin{tabular}{|l|c|c|}
\hline & Frequency & Percent (\%) \\
\hline Age at first usage of psychoactive substance(s) & & \\
\hline Less than 20 years & 41 & 33.6 \\
20 - 29 year & 61 & 50.0 \\
30 -39 years & 11 & 9.0 \\
40 - 49 years & 3 & 2.5 \\
Cannot remember & 6 & 4.9 \\
Total & 122 & 100.0 \\
\hline Feeling when first used psychoactive substance(s) & & \\
\hline Dizzy & 41 & 33.6 \\
Weak & 11 & 9.0 \\
\hline
\end{tabular}




\begin{tabular}{|l|c|c|}
\hline Strong & 37 & 30.3 \\
Sad & 3 & 2.5 \\
Depressed & 12 & 9.8 \\
Temporary insane & 13 & 10.7 \\
None & 5 & 4.1 \\
Total & 122 & 100.0 \\
\hline Are you still currently using the substance(s)? & & \\
\hline Yes & 115 & 94.3 \\
No & 7 & 5.7 \\
Total & 122 & 100.0 \\
\hline Frequency of using the substance(s) now & & \\
\hline Daily & 61 & 53.0 \\
Weekly & 37 & 32.2 \\
Monthly & 6 & 5.2 \\
Others & 3 & 2.6 \\
Undisclosed & 8 & 7.0 \\
Total & 115 & 100.0 \\
\hline Places where the substance(s) are easily bought & & \\
\hline Street stalls & 27 & 23.5 \\
Park/Garage along interstate route & 35 & 30.4 \\
Bar & 29 & 25.2 \\
House of dealer & 13 & 11.3 \\
Undisclosed & 11 & 9.6 \\
Total & 115 & 100.0 \\
\hline Amount spent in buying the substance(s) in the last 30 days (in Naira) & & \\
\hline $1-500$ & 11 & 9.6 \\
501 - 1000 & 21 & 18.3 \\
1001 - 1500 & 7 & 6.1 \\
1501 - 2000 & 25 & 21.7 \\
2001 - 2500 & 8 & 7.0 \\
2501 - 3000 & 17 & 14.7 \\
above 3000 Undisclosed & 23 & 20.0 \\
Total & 3 & 2.6 \\
& 115 & 100.0 \\
\hline
\end{tabular}

Source: Field Survey, 2017

Table 3 show respondents' age and feeling at their first usage of psychoactive substances as well as their current usage pattern. From the table, half ( 50.0 percent) of the respondents were between age 20-29 years when first used psychoactive substances, about 33.6 percent were less than 20 years of age when first used psychoactive substances, 9.0 percent were between age 30-39 years, 2.5 percent were between age 40-49 while 4.9 percent could not remember their age when first used psychoactive substances. Respondents were also asked about their feeling when first used psychoactive substances. Most (33.6 percent) of them felt dizzy, about 30.3 percent felt strong, 10.7 percent felt temporary insane, 9.8 percent felt depressed, 9.0 percent felt weak while the remaining 4.1 percent could not express their feeling.

Efforts were also made to know whether the respondents are still currently using psychoactive substances. Majority (94.3 percent) of them answered in the affirmative while the remaining 5.7 percent answered in the negative. On their frequency of using psychoactive substances, a little more than half (53.0 percent) of the respondents used it daily, about 32.2 percent used psychoactive substances weekly, few others (5.2 percent) used it monthly while the remaining respondents (7.0 percent) declined to disclose their frequency of psychoactive substances usage. With regards to the places of actual purchase of the psychoactive substances, many (30.4 percent) of the respondents indicated park/garage, some (25.5 percent) indicated bar, few others (23.5 percent) indicated street stalls, about 11.3 percent indicated house of dealers, while the remaining 9.6 percent refused to disclose the places where they easily bought psychoactive substance(s). On the amount they have spent in buying the substances in the last 30 days/4weeks/1month, many 
(21.7 percent) of the respondents had spent between $\mathrm{N} 1,501-\mathrm{N} 2,000$ in the last 30 days, some (20.0 percent) had spent above N3000, 18.3 percent of the respondents had spent between N501$\mathrm{N} 1,000,14.7$ percent had spent between N2, 501- N3, 000, few others (7.0 percent) had spent between N2, 000- N2, 500 while the remaining respondents (2.6 percent) declined to disclose the amount they have spent in buying psychoactive substances in the last 30 days/4 weeks $/ 1$ month.

\subsubsection{Objective 3: Reasons for the Use of Psychoactive Substances}

Table 4: Respondents' Reasons for the Use of Psychoactive Substances

\begin{tabular}{|c|c|c|c|c|c|c|c|c|c|}
\hline $\begin{array}{c}\text { No. in the } \\
\text { Questionnaire }\end{array}$ & Items & \begin{tabular}{|c|}
$\begin{array}{c}\text { Strongly } \\
\text { Agree }\end{array}$ \\
4 \\
\end{tabular} & \begin{tabular}{|c|} 
Agree \\
3 \\
\end{tabular} & \begin{tabular}{|c|} 
Disagree \\
2 \\
\end{tabular} & \begin{tabular}{|c|}
$\begin{array}{c}\text { Strongly } \\
\text { Disagree }\end{array}$ \\
1 \\
\end{tabular} & Fx & $\mathbf{N}$ & $\bar{x}$ & Rank \\
\hline 1 & To overcome depression & 65 & 44 & 5 & 8 & 410 & 122 & 3.36 & $1^{\text {st }}$ \\
\hline 10 & $\begin{array}{l}\text { To stay awake/alert throughout } \\
\text { the day/night of driving }\end{array}$ & 65 & 41 & 10 & 6 & 409 & 122 & 3.35 & $2^{\text {nd }}$ \\
\hline 4 & For pleasure & 60 & 48 & 4 & 10 & 402 & 122 & 3.30 & $3^{\text {rd }}$ \\
\hline 9 & To suppress driving fatigue & 56 & 52 & 8 & 6 & 402 & 122 & 3.30 & $4^{\text {th }}$ \\
\hline 7 & To overcome daily problems & 46 & 44 & 20 & 12 & 368 & 122 & 3.02 & $5^{\text {th }}$ \\
\hline 3 & To enhance my self confidence & 30 & 38 & 35 & 19 & 323 & 122 & 2.65 & $6^{\text {th }}$ \\
\hline 2 & $\begin{array}{l}\text { Because of the availability and } \\
\text { my accessibility to the } \\
\text { drugs/substances }\end{array}$ & 20 & 46 & 45 & 11 & 319 & 122 & 2.61 & $7^{\text {th }}$ \\
\hline 8 & To overcome shyness & 26 & 33 & 46 & 17 & 312 & 122 & 2.56 & $8^{\text {th }}$ \\
\hline 5 & To comply with peer norms & 24 & 30 & 46 & 22 & 300 & 122 & 2.46 & $9^{\text {th }}$ \\
\hline 6 & $\begin{array}{l}\text { Due to my lack of knowledge } \\
\text { about the drugs/substances } \\
\text { adverse effect }\end{array}$ & 18 & 26 & 45 & 33 & 273 & 122 & 2.24 & $10^{\text {th }}$ \\
\hline
\end{tabular}

Source: Field Survey, 2017

Table 4 show the reasons why respondents use psychoactive substances. From the table, majority of the respondents strongly agreed that they were using psychoactive substances to overcome depression, stay awake, seek pleasure, suppress driving fatigue, and to enhance their self confidence. In all, among the reasons indicated by the respondents for the use of psychoactive substances, 'to overcome depression' is the most common with overall mean of 3.36, followed closely by 'to stay awake' $x=3.35$, and to seek pleasure $x=3.30$, while using psychoactive substances 'to comply with peer norms' and 'due to my lack of knowledge about the substances' ranked last with the weighted mean of 2.46 and 2.24 respectively.

Respondents were further asked whether after quitting the driving job they would still continue using any of the psychoactive substances. Many (55.7 percent) of the respondents answered in the affirmative, about 42.6 percent answered in the negative while the few other (1.7 percent) were undecided. Those respondents who answered in the affirmative were further asked on why they think they will not quit the use of psychoactive substances, many of them interestingly said that they have used to psychoactive substances and without it they can't perform actively in their daily tasks, while a few other said they cannot do without it because of the pleasure they are deriving from it. This view however indicates that most of the respondents are addicted to psychoactive substances usage.

In addition to the foregoing, efforts were made to statistically find out whether respondents socio-demographic variables have any significant influence on their psychoactive substances usage by formulating the hypothesis below:

Ho: There is no significant relationship between respondents' socio-demographic variables and psychoactive substances usage

$\mathrm{Hi}$ There is significant relationship between respondents' socio-demographic variables and psychoactive substances usage

The result of the hypothesis is presented in table 5 below. 
Table 5: Relationship between respondents' socio-demographic variables and psychoactive substances usage

\begin{tabular}{|l|c|c|c|c|}
\hline Parameters & Mean & Std. Deviation & Pearson Value & Significant level \\
\hline Gender & 1.00 & 0.00 & -0.023 & 0.799 \\
\hline Age & 3.45 & 0.96 & 0.014 & 0.87 \\
\hline Marital status & 2.31 & 1.44 & 0.124 & 0.16 \\
\hline Educational level & 2.31 & 0.86 & 0.095 & 0.284 \\
\hline Religious affiliation & 1.84 & 0.75 & -0.074 & 0.405 \\
\hline Driving experience & 3.23 & 0.89 & -0.03 & 0.731 \\
\hline Ethnic group & 1.79 & 0.94 & -0.08 & 0.365 \\
\hline Driving hours & 2.45 & 0.83 & -0.022 & 0.803 \\
\hline Income & 24668.29 & 4264.48 & 0.077 & 0.397 \\
\hline
\end{tabular}

${ }^{*} \mathrm{NS}=$ Not significant $(p>0.05)$

Table 5 above shows the relationship between respondents' socio-demographic factors and psychoactive substances usage. From the table, the Pearson value of $-0.023,-0.074,-0.03,-0.08$, and -0.022 for Gender, Religious affiliation, Driving experience, Ethnic group and Driving hours respectively implies that there is weak negative correlation/relationship between respondents' psychoactive substances usage and Gender, Religious affiliation, Driving experience, Ethnic group, and Driving hours. The Pearson value of $0.014,0.124,0.095$, and 0.077 for Age, Marital Status, Educational level and Income respectively implies that there is respectively weak positive but imperfect correlation/relationship between respondents' psychoactive substances usage and Age, Marital status; Educational level, and Income. However, of these independent relationships, none exerts significant influence.

Efforts were further made to find out the effects/implications of psychoactive substances usage on the respondents and the results of the enquiries are shown in the table 6 below

\subsubsection{Objective 4: Effects of Psychoactive Substances Usage}

Table 6: Effects of Psychoactive Substances Usage on the Respondents

\begin{tabular}{|c|c|c|c|c|c|c|c|c|}
\hline $\begin{array}{c}\text { No. in the } \\
\text { Questionnaire }\end{array}$ & Items & \begin{tabular}{|c|} 
Never \\
1
\end{tabular} & \begin{tabular}{|c|} 
Sometimes \\
2
\end{tabular} & Always & Fx & $\mathbf{N}$ & $\bar{x}$ & Rank \\
\hline 8 & It makes me feel happy and relaxed & 15 & 40 & 67 & 296 & 122 & 2.43 & 1st \\
\hline 11 & $\begin{array}{l}\text { It keeps me awake and alert while driving most } \\
\text { especially at night }\end{array}$ & 20 & 50 & 52 & 276 & 122 & 2.26 & 2nd \\
\hline 9 & $\begin{array}{l}\text { It stimulates me to do things which ordinarily I } \\
\text { wouldn't be able to do without alcohol/drug }\end{array}$ & 25 & 48 & 49 & 268 & 122 & 2.20 & $3 r d$ \\
\hline 1 & It alter my moods and emotional state & 30 & 77 & 15 & 229 & 122 & 1.88 & 4th \\
\hline 7 & $\begin{array}{l}\text { Always make me to get into trouble with law } \\
\text { enforcement agents ( police, road safety officers, } \\
\text { vehicle inspection officers, etc) }\end{array}$ & 27 & 83 & 12 & 229 & 122 & 1.88 & 5 th \\
\hline 4 & $\begin{array}{l}\text { It leads to hangover and further involvement in } \\
\text { substance/drug use }\end{array}$ & 33 & 74 & 15 & 226 & 122 & 1.85 & 6th \\
\hline 5 & $\begin{array}{l}\text { It causes serious problem between me and my } \\
\text { boss/ wife/children/friend/relatives }\end{array}$ & 52 & 46 & 24 & 216 & 122 & 1.77 & 7th \\
\hline 2 & $\begin{array}{l}\text { It causes adverse effect on my health physically, } \\
\text { psychologically and socially }\end{array}$ & 43 & 73 & 6 & 207 & 122 & 1.70 & 8th \\
\hline 3 & $\begin{array}{l}\text { It affects my social life greatly (talking uncontrollably } \\
\text { and carelessly in the public, spending excessively, } \\
\text { loss of personal belonging, etc.) }\end{array}$ & 62 & 39 & 21 & 203 & 122 & 1.66 & 9th \\
\hline 6 & \begin{tabular}{|l|} 
It makes me engaged in unprotected pre/extra \\
marital sexual intercourse I often regret the next day
\end{tabular} & 62 & 47 & 13 & 195 & 122 & 1.60 & 10th \\
\hline 10 & $\begin{array}{l}\text { I always have difficulty in concentrating while } \\
\text { driving }\end{array}$ & 68 & 43 & 11 & 187 & 122 & 1.53 & 11th \\
\hline
\end{tabular}

Source: Field Survey, 2017 
Table 6 show the effect of psychoactive substances usage on the respondents. From the table, the use of psychoactive substances make majority of the respondents to always felt happy and relaxed, awake and alert while driving most especially at night, do things which ordinarily they wouldn't be able to do without the substances. These however sometimes result to alteration in the moods and emotional state of the respondents, get them into trouble with law enforcement agents such as police, road safety officers, vehicle inspection officers, etc, caused hangover and further involvement in substance use which adversely affect their health physically, psychologically and socially. In all, among the effects of psychoactive substances usage on the respondents as contained in the table 6 above, "it makes me feel happy and relaxed" is the most common with overall mean of 2.43 , followed closely by 'it keeps me awake and alert while driving most especially at night $(x=2.26)$, and 'it stimulates me to do things which ordinarily I wouldn't be able to do without psychoactive substance usage $(x=2.20)$ while 'I have difficulty in concentrating when driving' is the least with the mean of 1.53 .

Enquiries were also made from the respondents on whether they have experienced any form of road traffic accidents since the time they have been using psychoactive substances. The results of the enquiries revealed that a little more than half (54.1 percent) of the respondents indicated yes, meaning that they have experienced one form of road traffic accident or the other since the time they had been using psychoactive substances, while the remaining 45.9 percent answered in the negative. Those respondents who answered in the affirmative were further asked on the frequency of the accident. Majority (59.0 percent) of them indicated seldom/rarely, about 25.8 percent picked often while the remaining 15.2 percent choose very often. On the type of injuries sustained in the accidents by the respondents, most (48.5 percent) of them picked fracture, about 39.4 percent indicated other form of injuries such as avulsion injuries, head injuries, etc while the remaining 12.1 percent choose abrasions/cuts. In sum, this finding indicates that there is an association between psychoactive substance usage and road traffic accident. The finding was further examined statistically by formulating the hypothesis below:

Ho: There is no significant relationship between psychoactive substances usage and road traffic accident

$\mathrm{Hi}$ : There is significant relationship between psychoactive substances usage and road traffic accident

The result of the hypothesis is presented in table 7 below.

Table 7: Relationship between Psychoactive Substances Usage and Road Traffic Accident

\begin{tabular}{|c|c|c|c|c|c|c|}
\hline & & Psychoac & e Usage & & & \\
\hline & & Yes & No & Chı square $(x)$ & Df & sig. Value \\
\hline Road traffic accident & Yes & 66 & 1 & \multirow{3}{*}{0.196} & \multirow{3}{*}{1} & \multirow{3}{*}{0.023} \\
\hline & No & 56 & 7 & & & \\
\hline Total & & 122 & 8 & & & \\
\hline
\end{tabular}

*The relationship between psychoactive substances usage and road traffic accident is significant at $p<0.05$

The Chi-square Sig. value of 0.023 which is less than the conventional 0.05 level of significance indicates that psychoactive substances usage and road traffic accident are not independent. In other words, psychoactive substances usage and road traffic accident are related. This implies that there is a significant relationship between psychoactive substances usage and road traffic accident. This therefore means that psychoactive substances usage increases the risk of road traffic accidents among commercial road transport workers in the study area.

\section{Discussion of Findings}

The objectives of this study were to first, identify the types of psychoactive substances ever/never used by the respondents; second, find out the reasons for the use of psychoactive substances; third, investigate the frequency of using psychoactive substances; and fourth, examine the effects of psychoactive substances usage on commercial road transport workers in Lokoja, Nigeria. As 
regards the types of psychoactive substances ever/never used by the respondents, it was found that majority of them smoked cigarette, followed by distilled spirit and local alcoholic beverage, caffeine, etc. This finding conforms to that of Abiodun, et al (1994), Omolase, et al (2011) and Girotto, et al (2014). For instance, Abiodun, et al (1994) and Omolase, et al (2011) found in their separate studies that majority of psychoactive substances users started with alcohol and cigarette which, according to them, serve as gateway drugs to the use of other substances such as cocaine, heroin, amphetamine, inhalants, hallucinogens, etc while Girotto, et al (2014) found amphetamines as the drug being used primarily by truck drivers.

With regards to the reasons for the use of psychoactive substances, it was discovered in the study that majority of the respondents used psychoactive substances to overcome depression. This finding supported that of Breslau, et al (1991); Halperin, et al (2010); and Saravana \& Heldhy (2014). These scholars in their separate studies found that individual with a history of major depression are more likely to develop nicotine dependence. Other major reasons given by the respondents for their use of psychoactive substances include to stay awake, suppress driving fatigue, overcome daily problems and for pleasure. These findings conform to that of Makanjuola, et al (2007); Rasheed (2010); Omolase, et al (2011); Adadu, et al (2012); Okpataku (2015); Arnold, et al (1997); and Philip, et al (1999). For instance, Arnold, et al (1997) and Philip, et al (1999) in their separate studies found both truck and long distance driving as a deadliest profession involving drivers engaging road for a long period of time including night. This subgroup of people by virtue of their job are fatigue prone and require keeping awake both of which were found as the major reasons for psychoactive substances usage.

Also, on the hypothesised relationship between respondent socio-demographic factors and psychoactive substances usage, it was discovered that none of the socio-demographic variables (gender, age, marital status, educational level, religious affiliation, years of driving experience, ethnic groups, driving hours and income exerts significant influence on respondents psychoactive substances usage. This finding however contradicted that of Makanjuola, et al (2014); and Okpataku (2016). For instance, Makanjuola, et al (2014) found a significant association between age, level of education, driving experience and psychoactive substances usage. Likewise, Okpataku (2016) in his study titled Socio-demographic Correlates of Substances Use Among Long Distance Commercial Vehicle Drivers found that religion (both Christian and Islam), education (especially those with formal education), marital status (especially those who never married), and age (those below 45 years), exerts significant influence on psychoactive substance usage. The difference in the findings of Makanjuola, et al (2014); and Okpataku (2016), and that of the current study may however be due to differences in research setting and instrument used.

On the frequency of using psychoactive substances by the respondents, it was discovered in the study that majority (53.0 percent) of them used it daily while the remaining (47.0 percent) used psychoactive substances either weekly or monthly. This finding conform to that of Makanjuola, et al, (2014); Adekoya, Adekoya, Adepoju \& Owoeye (2011), as they found in their separate studies the prevalence of daily alcoholic consumption as well as cigarette smoking and eating of kola nut among commercial drivers while driving.

On the effects of psychoactive substances usage on the respondents, it was discovered that psychoactive substances usage sometime affect respondents in such a way that it alter their moods and emotional state; get them into trouble with law enforcement agents such as police, road safety officers, vehicle inspection officers; caused hangover and further involvement in substances use which adversely affect their health physically, psychologically and socially. These findings conform to that of Bates \& Blakely (1999); Makanjuola, et al (2007); and Adadu, et al (2012).

On the hypothesised relationship between psychoactive substances usage and road traffic accident, it was discovered in the study that there is a significant relationship between psychoactive substances usage and road traffic accident. This finding supported that of Bates \& Blakely (1999); Makanjuola, et al (2007); Welcome \& Pereverzew (2010); Omolase, et al (2011); Usman \& Ipinmoye, (2015); Gudaji \& Dankishiya (2016); and Okafor, Udofia \& Onyuku (2016), indicating significant relationship between psychoactive substances usage and road traffic accident and violations. Welcome \& Pereverzew (2010) further found that 50 percent of accidents, and its attendant consequences, on Nigerian roads are due to psychoactive substances usage. 


\section{Conclusion and Recommendations}

This study examined the rationale and implications of psychoactive substance use among commercial road transport workers in Lokoja, Nigeria. Results of the study show that majority of the respondents used psychoactive substances to overcome depression, stay awake while driving, suppress driving fatigue, overcome daily problems and for pleasure. These however were found to sometimes result in alteration in the moods and emotional state of the respondents, road traffic accidents, hangover and further involvement in substances usage which adversely affect their health physically, psychologically and socially. The results of the hypotheses testing revealed that there is a significant relationship between psychoactive substances usage and road traffic accident. In view of the aforementioned findings, the study concludes that government efforts at preventing the use of psychoactive substances in parks/garages have not been so effective in the study area. Correspondingly, it is recommended that Government at all levels (federal, state and local) should intensify campaign through print and electronic media as well as by organising seminar and workshop for members of commercial road transport workers not only in the study area but also in Nigeria generally, on the risks (social, psychological and health) of psychoactive substance usage.

\section{Limitations and Directions for Future Research}

This study was cross sectional; therefore causal conclusions cannot be drawn. Prospective studies are therefore needed to follow up psychoactive substances usage and factors associated with their intake. Secondly, this study was limited to members of commercial road transport workers in Lokoja, Nigeria, therefore the findings of the study cannot be applied to all commercial road transport workers in Kogi State. Further study is needed with a large sample of member of commercial road transport workers in Kogi State generally or in other climate to validate the findings of this study as well as identify any intrinsic differences among commercial road transport workers who choose not to use psychoactive substances, those who use it but not continue, and those who progress to habitual level.

\section{References}

Abiodun, O.A., Adelekan, M.L., Ogunremi, O.O., Oni, G.A \& Obayan, A.O. (1994). Psychosocial correlates of alcohol, tobacco and cannabis use amongst secondary school students in Ilorin, Nigeria, West African Journal of Medicine, 13(4),213-217, October-November.

Adadu, P.M.A.,Akpama, E.G \& Ekanem, R.S. (2012). The challenges of socio-psychological factors as correlates of adolescent students' cigarette smoking in Cross River, Nigeria, African Research Review: An International Multidisciplinary Journal, 6(1),393-401, DOI: http://dx.doi.org/10.4314/afrrev.v6il.31

Adekoya, B.J., Adekoya, A.O., Adepoju, F.G \& Owoeye, J, F.A. (2011). Driving under influence among long distance commercial drivers in Ilorin, Nigeria, International Journal of Biological and Medical Research, 2(4), 870-873

Aina, O.F \& Olorunshola, D.A. (2008). Alcohol and substance use portrayals in Nigerian video tapes: An analysis of 479 films and implications for public drug education, International Quarterly of Community Health Education, 28(1), 63-71, DOI:10.2190/1Q.28.1.f

Ansari, W., Labeeb, S., Kotb, S \& Stock, C. (2012). Correlates of smoking, quit attempts and attitudes towards total smoking bans at university: Findings from eleven faculties in Egypt, Asian Pacific Journal of Cancer Prevention, 13(6), 2547-2556, DOI: 10.7314/APJCP.2012.13.6.2547

Arnold, P.K., Hartley, L.R., Corry, A., Hochstadt, D., Penna, F \& Feyer, A.M. (1997). Hours of work, and perceptions of fatigue among truck drivers, Accident Analysis and Prevention, 29(4), 471-7, July

Bates, M, N \& Blakely, T.A. (1999). Role of cannabis in motor vehicle crashes, Epidemiology Reviews, 21(2), 222-232

Becker, H, S (1953) Becoming a Marihuana user, American Journal of Sociology, 59, 235-242

Breslau, N., Kilbey, M \& Andreski, P. (1991). Nicotine dependence, major depression, and anxiety in young adults, Archive of General Psychiatry, 48(12), 1069-74. DOI: 10.1001/archpsyc.1991.01810360033005

Caleyachetty, R., Echouffo-Tcheugui, J.B., Stephenson, R \& Muennig, P. (2014). Intimate partner violence and current tobacco smoking in low-middle income countries: Individual participant meta-analysis of 231,892 women of reproductive age, Global Public Health, 9(5), 570-8, DOI: 10.1080/17441692.2014.905616 
Centre for Disease Control and Prevention. (2012). Surveillance summaries, morbidity and mortality, Weekly Report, 61(4), 1-162

Didilescu, A., Inagaki, K., Sfeateu, R., Hanganu, S.C \& Virtanen, J.I. (2014). Smoking habits and social nicotin dependence among dental students in Romania, Oral Health and Dental Management, 13(1), 35-40, March, Retrieved from https://www.ncbi.nlm.nih.gov/.../246039, on 10/4/17

Ebie, J.C. (2008). Overview of demand reduction. In handbook of the African training courses on drug dependence, Pp 1-5

Fawibe, M \& Shittu, A.O. (2011). Prevalence and characterstics of cigarette smokers among undergraduate of the University of Ilorin, Nigeria, Nigerian Journal of Clinical Practice, 14(2), 201-5, DOI: 10.4103/11193077.84016

Girotto E., Mesas, A.E., deAndrade, S.M \& Birolim. M. M (2014). Psychoactive substance use by truck drivers: a systematic review, Occupational and Environmental Medicine, 71, 71-76

Girotto, E., deAndrade, S.M., Mesas, A.E., Gonzalez, A.D \& Guidoni, C.M (2015). Working conditions and illicit psychoactive substance use among truck drivers in Brazil, Occupational and Environmental Medicine, 72,764-9

Gudaji M.I \& Dankishiya, F.S. (2016). Relationship between road traffic law violation, accident and psychoactive substances use among commercial motorcycle operator in Kano, North Western Nigeria, International Journal of Medicine and Medical Science, 8(2), 15-21

Hanson D.J \& Engs, R.C. (1992). College students' drinking problems: A national study 1982-1991, Psychological Report, 91, 39-42

Halperin, A.C., Smith, S.S., Heiligenstein, E., Brown, D \& Fleming, M.F. (2010). Cigarette smoking and associated health risks among students at five universities, Nicotine and Tobacco Research, 12(2), 96104, DOI: 10.1093/ntr/ntp182

Haukkala,A., Uutela, A., Vartiainen, E., Mcalister, A \& Knekt, P.C. (2000). Depression and smoking cessation: The role of motivation and self-efficacy, Addictive Behaviour, 25(2), 311-316, March-April. DOI: 10.1016/50306-4603(98)00125-7

Hisam, Z. (2006). Road transport workers in Pakistan, Pakistan: Pakistan Institute of Labour Education and Research

Ihezue, U.H. (1988). Drug abuse among medical students at a Nigerian university: Prevalence and pattern of use, Journal of National Medical Association, 80(1), 81-85, January, PMCID: PMC2625685

Makanjuola, A.B., Aina, O.F \& Onigbogi, L. (2014). Alcohol and other psychoactive substance use among tanker drivers in Lagos, Nigeria, European Scientific Journal, 10(15), 545-559

Makanjuola, A.B., Oyeleke, A.S \& Akande, T.M. (2007). Psychoactive substance use among long distance vehicle driver in llorin, Nigerian Journal of Psychiatry, 5(1), 14-18

Mee, S (2014) Self-efficacy: A mediator of smoking behaviour and depression among college students, Pediatric Nursing, 40(1), 9-37, January-February. Retrieved from https://www.ncbi.nlm.nih.gov/../247579..., on 10/04/17

Mergen, H., Mergen, B.E., Tavli, V., Ongel, K \& Tan, S. (2011). Assessment of smoking behaviour of 2509 Turkish University students and its correlates: A cross-sectional study, Tuberculosis and Thorax, 59, 12631, Retrieved from https://www.ncbi.nlm.nih.gov/.../217403, on 10/03/17

National Bureau of Statistics. (2016). Nigerian gross domestic product report, Retrieved from https://www.nigerianstat.gov.ng, on 12/04/17

Okafor, C.J., Udofia, O \& Onyuku, T. (2016). Pattern of psychoactive substance use among long distance commercial drivers in Calabar, Nigeria, International Neuropsychiatric Disease Journal, 8(3), 1-9, DOI: 10.9734/INDJ/2016/29676

Okpataku, C.I. (2015). Pattern and reasons for substance use among long distance commercial drivers in a Nigerian city, Indian Journal of Public Health, 59(4), 259-63, October-November, DOI: 10.4103/0019$557 X .169649$

Okpataku, C.I. (2016). Sociodemographic correlates of substance use among long distance commercial vehicle drivers, Journal of Medicine in the Tropics, 18(1), 6-18. Retrieved from https://www.jmedtropics.org/texasp?2016/18/1/6/176053, On 13/2/17

Omolase, B.O., Afolabi, O.T \& Omolase, C.O. (2011). Drink driving among commercial drivers in a Nigerian community, Middle East Journal of Psychiatry and Alzheimers, 2(2), 15-19, July

Peltzer, K. (2001). Tobacco use among black South African University students: Attitude, risk awareness and health locus of control, Curationis, 24(2), 4-8, May. Retrieved from https://www.ncbi.nlm.nih.gov/pubmed/11885474, on 08/03/17

Philip, P., Taillard, J., Guilleminault, C., Quera, S.M.A., Bioulac, B \& Ohayon, M. (1999). Long distance driving and self induced sleep deprivation among automobile drivers, Sleep, 22(4), 475-80, June

Presley, C.A., Meilman, P.W \& Lyeria, R. (1993). Alcohol and drugs in American college campuses: Use, consequences and perceptions of the campus environment, volume 1: 1989-1991, Carbondale, IL: The Core Institute, Southern Illinos University 
Rasheed, K.O \& Ismaila, A. A. (2010). Tracing the path of substance use among students of tertiary institutions in Lagos State, Nigeria, International Journal of Academic Research, 2(1), 216-223

Rasheed, K.O. (2010). The desire to remain awake at night among students of tertiary institution in Lagos State, Nigeria: The health implications, International Journal of Academic Research, 2(2), 29-34

Rozi, S., Butt, Z.A \& Akhtar, S. (2007). Correlates of cigarette smoking among male college students in Karachi, Pakistan, BMC Public Health, 7, 312, November, DOI: 10.1186/1471-2458-7-312

Saravanan, C \& Heidhy, I. (2014). Psychological problems and psychosocial predictors of cigarette smoking behaviour among undergraduate students in Malaysia, Asian Pacific Journal of Cancer Prevention, 15(18), 7629-34. DOI: 10.7314/APJCP.2014.15.18.7629

Sen, I \& Basu, A. (2000). Factors influencing smoking behaviour among adolescents, Asian Pacific Journal of Cancer Prevention, 1(4), 305-309, February. Retrieved from https://www.ncbi.nlm.nih.gov/.../127163, on $07 / 03 / 17$

Sinha, D.N \& Gupta, P.C. (2007). Tobacco use among students and school personnel in India, Asian Pacific Journal of Cancer Prevention, 8(3), 417-21, July, PMID: 18159980

Thakur, J.S., Prinja, S., Bhatnagar, N \& Sinha, D. (2013). Socioeconomic inequality in the prevalence of smoking and smokeless tobacco use in India, Asian Pacific Journal of Cancer Prevention, 14(11), 6965-9, DOI:10.7314/APJCP.2013.14.11.6965

Unackwukwu, G.C \& Nwankwo, C.A. (2003). Drug dependence among the youth of Nigeria: Implication for development, The Educational Psychologist, 1, 85-103

United Nations Office on Drugs and Crime. (2016). World drug report, Vienna, NewYork: United Nations Publication, Sales No. E.16.X1.7

Usman, S.O \& Ipinmoye, T.O. (2015). Driving under influence among long distance commercial drivers in Akure, South West Region, Nigeria, Journal of Environmental and Occupational Science, 4(3), 128-131, DOI: 10.5455/JEOS.20150630111726

Welcome N, Pereverzew O (2010) Socio-demographic correlates of substance use among long distance commercial vehicle drivers, Journal of Medicine in the Tropics, 18, 6-18.

Witters, W., Venturelli, P.J \& Hanson, G.R. (2006). Drugs and society, London: Zones and Barlett 